\title{
SIBUTRAMINA: FALHAS E INCOMPLETUDE DE DOCUMENTOS NA PRESCRIÇÃO E DISPENSAÇÃO
}

\author{
SIBUTRAMINA: FAILED AND INCOMPLETE DOCUMENTS ON PRESCRIPTION AND DISPENSING
}

\section{Syliana Sana Silva de Souza ${ }^{a}$, Mirian Talita Reis Santos Pinheiro ${ }^{b}$, Paulo Henrique Ribeiro Fernandes Almeida ${ }^{c}$, Lucas Brasileiro Lemos ${ }^{\mathrm{d}}$, Gisele da Silveira Lemos ${ }^{\mathrm{e}}$}

\author{
ªylisana@hotmail.com, ${ }^{\text {}}$ miriamtalita@hotmail.co ${ }^{\mathrm{m}}$, 'benriqueribeiro.farm@gmail.com, cbrasileirolemos@gmail.com, \\ egiselesilveiralemos@gmail.com \\ Universidade Estadual do Sudoeste da Bahia - Vitória da Conquista (BA), Brasil
}

Data de recebimento do artigo: 25/08/2016

Data de aceite do artigo: 15/02/2017

\section{RESUMO}

Introdução: A sibutramina é atualmente o único fármaco usado para o tratamento da obesidade com registro no Brasil. As exigências para sua prescrição e dispensação aumentaram com a Resolução no 52 que entrou em vigor em dezembro de 2011. Objetivo: Este estudo teve como objetivo avaliar o impacto dessa resolução na comercialização do medicamento, além de falhas e erros no processo de prescrição/ dispensação em uma farmácia comunitária. Metodologia: Foram analisadas 741 notificaçóes de receita de sibutramina e 258 termos de responsabilidade do prescritor, retidos na farmácia comunitária, referentes ao período de janeiro de 2010 a junho de 2014. Esses documentos foram analisados quanto à completude e legibilidade de dados obrigatórios segundo as legislaçôes vigentes no país e agrupados em dois períodos antes e após a Resoluçáo 52/2011. Resultados: Os resultados mostram um aumento estatisticamente significativo da completude, com diminuição das falhas, do primeiro para o segundo período $(\mathrm{p}<0,05)$, assim como a diminuição do consumo no segundo período e predominância de prescrição com nome de marca em detrimento do genérico. Conclusóes: Os resultados indicam que as novas legislaçóes e o aumento da fiscalização foram capazes de reduzir a comercialização de sibutramina e o número de erros e falhas na prescrição e dispensaçáo no período estudado.

Palavras-chave: Sibutramina; obesidade; farmácia comunitária.

\section{ABSTRACT}

Introduction: Sibutramine is currently the only drug used for the treatment of obesity with registration in Brazil. The requirements for its prescribing and dispensing increased with the Resolution No. 52, which entered into force in December 2011. Objective: To evaluate the impact of this resolution on the commercialization of the product as well as failures and mistakes in the process of prescribing and/ or dispensing it in a community pharmacy. Methods: We analyzed 741 reports of sibutramine revenue and 258 terms of prescribing responsibility, retained in the community pharmacy, reffering to the period from January 2010 to June 2014. These documents were reviewed for completeness and readability of the required data in accordance with current laws in Brazil and grouped into two periods: before (1) and after (2) the Resolution No. 52. Results: Results show a statistically significant increase in completeness, with reduction of failures, from the first to the second period $(\mathrm{p}<0.05)$, as well as the decline in sales in the second period and prevalence of brand-name prescriptions instead of generic. Conclusions: Results indicate that the new laws and the increased enforcement were able to reduce the commercialization of sibutramine and the number of errors and failures in prescribing and dispensing the study period.

Keywords: Sibutramine; obesity; community pharmacy. 


\section{Introdução}

Os índices da população com sobrepeso e obesidade estáo aumentando em todo o mundo e, principalmente, nos centros urbanos. Existem inúmeras pesquisas científicas direcionadas ao estudo das causas do desenvolvimento da obesidade que é definida pela Organização Mundial de Saúde (OMS) como o acúmulo anormal ou excessivo de gordura. A obesidade é considerada um problema de saúde pública por ser fator de risco para muitas doenças crônicas, como o diabetes, as doenças cardiovasculares e alguns tipos de câncer, além de distúrbios psicossociais, como depressão, transtornos de ansiedade e alteração da imagem corporal ${ }^{1}$.

O tratamento da obesidade deve ter como base a mudança nos hábitos alimentares, a realização de atividades físicas, a busca de apoio psicológico e acompanhamento médico. As técnicas cirúrgicas e o tratamento farmacológico são recomendados em associação a mudanças de estilo de vida e, apenas, quando o paciente não consegue redução satisfatória de peso e tiver um índice de massa corpórea (IMC) acima de $30 \mathrm{~kg} / \mathrm{m}^{2}$. A escolha do tratamento mais efetivo deve levar em consideraçáo a presença de outras comorbidades como hipertensão arterial sistêmica, dislipidemias e diabetes tipo II, bem como a gravidade do paciente ${ }^{2}$.

Entre os métodos farmacológicos para o tratamento da obesidade, o uso de sibutramina é atualmente a terapia de primeira escolha, pois apresenta duas maneiras de controlar a obesidade como inibidor do apetite: aumentando a sensação de saciedade e impedindo a redução da taxa metabólica, levando a perda de peso ${ }^{3}$.

A sibutramina é um medicamento considerado novo no mercado, e pesquisas recentes trouxeram dúvidas quanto a sua segurança em algumas situaçóes especiais por aumentar o risco de doenças cardiovasculares. Portanto, a partir da Resolução da Diretoria Colegiada (RDC) no 52, de 6 de outubro de 20114, que complementa a Portaria no 344 , de 12 de maio de $1998^{5}$, e a RDC no 58 , de 5 de setembro de $2007^{6}$, deve ser apenas dispensada, mediante prescrição médica em receituário azul $\mathrm{B} 2$ com dosagem máxima diária de $15 \mathrm{mg}$, acompanhada de termo de responsabilidade entre médico e paciente, em três vias, norma esta regulamentada pela Agência Nacional de Vigilância Sanitária (Anvisa).

Apesar da liberação recente da comercialização de mazindol, femproporex e anfepramona através da RDC no 50 , de 25 de setembro de $2014^{7}$, a sibutramina é o único fármaco anorexígeno que está sendo comercializado para tratamento da obesidade no Brasil, devido ao registro dos outros anorexígenos ainda não terem sido concedidos.

A notificação de receita e o termo de responsabilidade do prescritor são documentos necessários para a venda da sibutramina ${ }^{4}$. Devem conter todas as informaçóes de identificaçáo do paciente e do prescritor e aquelas importantes para permitir interlocução entre o prescritor, o dispensador e o paciente a fim de que se realize o tratamento correto. Portanto, precisam cumprir alguns requisitos legais e seguir um modelo-padrão com itens essenciais estabelecidos pelos órgãos competentes a nível nacional. A notificação de receita é normatizada pela autoridade sanitária seguindo modelo padrão. Obrigatoriamente devem ser totalmente preenchidos pelo prescritor devidamente habilitado e observados atentamente pelo farmacêutico no ato de dispensação ao paciente. Não devem conter rasuras nem abreviaturas não padronizadas e ser legível. Essas adequaçóes aos requisitos técnicos e legais são importantes para prevenir fraudes, falsificaçōes, erros de medicação e o uso ilícito. Além de reduzir riscos de reaçóes adversas e efeitos colaterais e favorecer a adesão do paciente ao tratamento ${ }^{8,9}$.

Considerando o impacto social, de saúde e econômico da obesidade, o uso da sibutramina e a crescente preocupação mundial com o uso racional dos medicamentos, torna-se importante a realização de estudos que possam identificar falhas e incompletude para possíveis soluçóes no processo prescrição/dispensação/tratamento. Dessa forma, justifica-se a realização deste estudo para analisar o perfil de consumo de sibutramina no município de Jequié, Bahia, avaliando o preenchimento legal dos documentos obrigatórios para a dispensação de sibutramina: a notificação de receita tipo $\mathrm{B} 2$ e o termo de responsabilidade do prescritor além de avaliar o impacto da RDC 52/2011 na comercialização de sibutramina.

\section{Metodologia}

Foi realizado estudo transversal, retrospectivo, com base em análise documental de notificaçôes de receita B2 e termo de responsabilidade do prescritor para uso de sibutramina, disponibilizadas por uma farmácia comunitária localizada no centro da cidade de Jequié, sudoeste da Bahia, com população estimada de 165.345 habitantes ${ }^{10}$. A farmácia comunitária, onde os dados foram coletados, é a matriz de uma rede com quatro (04) filiais, funciona de segunda a domingo no horário de 7 as 23 horas, com uma equipe de trabalho composta por dois profissionais farmacêuticos em cada turno de trabalho e por auxiliares. 
A notificação de receita e o termo de responsabilidade do prescritor após a dispensação do medicamento passam a ser documentos do estabelecimento farmacêutico, que deverão prestar as informaçóes ou proceder à entrega de documentos, nos prazos fixados, a fim de não obstarem a ação de vigilância sanitária conforme art. 88 da Portaria 344/1998 e esses documentos devem ficar arquivados por dois anos, para atender a qualquer inspeção sanitária, depois incinerados. Esses documentos são utilizados também para a escrituração semanal que deve ser enviada à Anvisa pela farmácia utilizando o Sistema Nacional de Gerenciamento de Produtos Controlados (SNGPC).

A amostra foi constituída por notificaçóes da receita de sibutramina, que se enquadra na Lista B2 dos medicamentos sob controle especial da Portaria $344 / 1998^{5}$ e os termos de responsabilidade conforme RDC 52/2011, que foram retidos na farmácia no momento da dispensaçáo do medicamento. A coleta ocorreu nos meses de julho a outubro de 2014, totalizando 741 notificaçóes de receita de sibutramina e 258 termos de responsabilidade, referentes ao período de janeiro de 2010 a junho de 2014 . O período de coleta abrangeu a totalidade dos documentos arquivados na farmácia, que mantinha um arquivo correspondente ao período de cinco anos, obedecendo às normas sanitárias que designam o período mínimo de dois anos para todos os documentos de medicamentos sob controle especial, com exceção dos anabolizantes.

O instrumento de coleta utilizado foi um formulário de avaliação estruturado utilizando critérios pré-estabelecidos. As variáveis ou grupos de variáveis estudadas foram:

- Itens de preenchimento obrigatório pelo médico prescritor: informaçóes do paciente (nome, endereço); informaçōes do prescritor (carimbo, assinatura do profissional, número de inscrição no respectivo Conselho Profissional - CRM, especialidade médica, endereço e telefone da clínica ou hospital); e informaçôes do medicamento (nome, concentração, forma farmacêutica, via de administração, dose, frequência diária de administração, duraçấo do tratamento, data da prescrição e instruçóes complementares sobre o modo de usar o medicamento);

- Itens de preenchimento obrigatório pelo profissional dispensador (carimbo e assinatura do farmacêutico, número do lote do medicamento, data da dispensação e quantidade dispensada) e dados do comprador (nome, endereço e o $\mathrm{n}^{\circ}$ do registro geral - RG dado à cédula de identidade);

- Informaçóes obrigatórias na notificação de receita: cor da notificação de receita, identificação da notificação - B2, número da notificação, identificação da gráfica e numeraçẫo de autorização repassada pela Vigilância Sanitária para confecção do talonário;

- Completude e legibilidade do termo de responsabilidade do prescritor após a RDC 52/20114: informaçóes do paciente (nome, endereço, idade, sexo, número do RG e diagnóstico); informações do prescritor (carimbo, assinatura do profissional, número de inscrição no respectivo Conselho Profissional e especialidade médica) e data do termo.

O processamento dos dados foi realizado utilizando os programas Microsoft Office Excel 2013, como banco de dados para transcrever as informaçóes coletadas das notificaçôes de receita e dos termos de responsabilidade do prescritor e para análise dos dados foi utilizado o programa SPSS Statistics for Windows (IBM SPSS, 21.0, 2012, Armonk, NY: IBM Corp.). Para análise dos dados foi realizada a distribuição de frequência das variáveis estudadas, organizando-as em tabelas e gráficos. $\mathrm{Na}$ análise estatística de associação entre as variáveis foram aplicados os testes Qui-quadrado. Nos casos em que a frequência esperada foi menor que cinco $(n<5)$, foi utilizado o teste exato de Fisher. O nível de significância adotado foi de $5 \%(\alpha=0,05)$.

\section{Resultados}

Foram analisadas 741 notificaçóes de receitas de sibutramina aviadas na farmácia comunitária no período do estudo, através das quais verificou-se maior consumo em 2010 com 272 prescriçóes aviadas, 216 em 2011, 115 em 2012, 88 em 2013 e uma média de 100 notificaçóes em 2014, ou seja, houve uma queda no consumo de sibutramina, após publicação de duas resoluçóes que aumentaram o controle da prescrição e dispensação desse medicamento.

\section{Itens de preenchimento obrigatório pelo médico prescritor}

A Tabela 1 apresenta a frequência dos dados de preenchimento obrigatório pelo médico prescritor das notificaçōes analisadas. Todas as 741 prescriçóes analisadas estavam escritas à tinta e em idioma português brasileiro 
como prevê a legislação. Os resultados foram agrupados em dois períodos: primeiro período - antes da RDC 52/2011, entre janeiro de 2010 e dezembro de 2011, e segundo período - depois da RDC 52/2011, de janeiro de 2012 a junho de 2014. Foi considerado "Sim", para o preenchimento completo e legível do item; "Não", para a ausência do preenchimento ou quando houve dificuldade na leitura por mais de duas pessoas (ilegível).

Tabela 1: Distribuição dos componentes de preenchimento obrigatório do médico prescritor em notificações de sibutramina, analisadas em uma farmácia comunitária no município de Jequié/BA, entre janeiro de 2010 e junho de 2014.

\begin{tabular}{|c|c|c|c|c|c|}
\hline \multirow[b]{2}{*}{ Itens avaliados } & \multicolumn{2}{|c|}{ Jan/2010 a Dez/2011 } & \multicolumn{2}{|c|}{ Jan/2012 a Jun/2014 } & \multirow[b]{2}{*}{$\mathbf{p}^{* * *}$} \\
\hline & $\begin{array}{c}\text { Sim } \\
\mathrm{Fa}^{*} \\
\left(\mathrm{Fr}^{* *} \%\right)\end{array}$ & $\begin{array}{c}\text { Náo } \\
\text { Fa* }^{*} \\
\left(\mathrm{Fr}^{* *} \%\right)\end{array}$ & $\begin{array}{c}\text { Sim } \\
\mathbf{F a}^{*} \\
\left(\mathrm{Fr}^{* *} \%\right)\end{array}$ & $\begin{array}{c}\text { Náo } \\
\text { Fa* }^{*} \\
\left(\mathrm{Fr}^{* * \%}\right)\end{array}$ & \\
\hline Nome completo do paciente & $464(95,1)$ & $24(4,9)$ & $250(98,8)$ & $3(1,2)$ & 0,012 \\
\hline Endereço completo do paciente & $159(32,5)$ & $329(67,5)$ & $173(68,4)$ & $80(31,6)$ & $<0,001$ \\
\hline Nome completo do emitente & $456(93,4)$ & $32(6,6)$ & $242(95,6)$ & $11(4,4)$ & 0,250 \\
\hline Número do CRM & $440(90,1)$ & $48(9,9)$ & $243(96)$ & $10(4)$ & 0,004 \\
\hline Endereço do consultório/instituição & $488(100)$ & $0(0)$ & $253(100)$ & $0(0)$ & - \\
\hline Assinatura e carimbo do emitente & $450(92,2)$ & $38(7,8)$ & $242(95,6)$ & $11(4,4)$ & 0,086 \\
\hline Nomenclatura oficial (DCB/DCI) & $184(37,7)$ & $304(62,3)$ & $128(50,6)$ & $125(49,4)$ & 0,001 \\
\hline Concentração & $481(98,5)$ & $7(1,5)$ & $245(96,8)$ & $8(3,2)$ & $<0,001$ \\
\hline Forma farmacêutica & $326(66,8)$ & $162(33,2)$ & $223(88,1)$ & $30(11,9)$ & $<0,001$ \\
\hline Posologia & $375(76,8)$ & $113(23,2)$ & $239(94,4)$ & $14(5,6)$ & $<0,001$ \\
\hline Data da prescriçáo & $347(71,1)$ & $139(28,9)$ & $234(92,5)$ & $19(7,5)$ & $<0,001$ \\
\hline
\end{tabular}

Fonte: Elaborado pelos autores a partir dos dados coletados.

Legenda: CRM: Conselho Regional de Medicina; DCB/DCI: Denominação Comum Brasileira/Denominação Comum Internacional; Fa*: frequência absoluta; $\mathrm{Fr}^{* *}$ : frequência relativa; ${ }^{* * *}$ p-valor $<0,05$.

Com relação aos itens referentes ao emitente, o nome e o número da inscrição no Conselho Profissional foram os dados com maior frequência $(93,4 \%$ e $90,1 \%$ no primeiro período e $95,6 \%$ e 96,5 no segundo período). Quanto à origem das notificaçôes, ou seja, endereço completo do consultório ou instituição, todas as notificaçôes avaliadas apresentavam este item corretamente preenchido já impresso na notificaçấo ou carimbado, $76,10 \%$ foram de origem de consultórios ou instituiçôes privadas e $23,9 \%$ do Sistema Único de Saúde (SUS).

A Denominação Comum Brasileira (DCB) foi utilizada em $37,7 \%$ das notificaçóes analisadas no primeiro período e em $50,6 \%$ no segundo período. O nome comercial foi adotado em $62,3 \%$ das notificaçóes no primeiro período e em 49,4\% no segundo período. Das notificaçóes que apresentavam o nome comercial, cinco marcas foram citadas, incluindo a marca de referência no mercado brasileiro o Biomag que correspondeu a $22,8 \%$, Síbus ${ }^{\oplus} 39,6 \%$, Slenfig ${ }^{\oplus} 34,3 \%$, Vazy $^{\oplus}$ $2,6 \%$ e Plenty ${ }^{\circ} 0,7 \%$. A quantidade prescrita em unidades esteve ausente em uma notificação, em $71 \%$ foi prescrita uma caixa, $23 \%$ duas caixas e $6 \%$ três caixas.
Analisando a especialidade médica de cada prescritor, observou-se que $45 \%$ das notificaçôes apresentavam este item e que destes o maior número de prescriçôes $(26,95 \%)$ foi de clínicos gerais, seguidos por endocrinologistas $(23,65 \%)$ e cardiologistas $(10,78 \%)$, mas também verificou-se a presença de homeopatas, ginecologistas, ortopedistas, otorrinolaringologistas, nutrólogos entre outros.

\section{Itens de preenchimento obrigatório pelo profissional dispensador}

A distribuição da frequência dos dados de preenchimento obrigatório pelo farmacêutico, avaliados neste estudo, está apresentada da Tabela 2. O item com maior ausência nos dois períodos foi a assinatura e o carimbo do farmacêutico com $87,9 \%$ no primeiro e $98,4 \%$ no segundo período.

$\mathrm{O}$ registro da quantidade dispensada em unidades deve ser feito pelo farmacêutico no verso da notificação. Uma notificação não apresentava o registro dessa informação, em $81,1 \%$ das notificações foi dispensada uma caixa e em $18,9 \%$ foram dispensadas duas caixas. 
Tabela 2: Distribuição dos componentes de preenchimento obrigatório pelo profissional dispensador em notificações de sibutramina, analisadas em uma farmácia comunitária no município de Jequié/BA, entre janeiro de 2010 e junho de 2014.

\begin{tabular}{|c|c|c|c|c|c|}
\hline \multirow[b]{2}{*}{ Itens avaliados } & \multicolumn{2}{|c|}{ Jan/2010 a Dez/2011 } & \multicolumn{2}{|c|}{ Jan/2012 a Jun/2014 } & \multirow[b]{2}{*}{$\mathbf{p}^{* * *}$} \\
\hline & $\begin{array}{c}\text { Sim } \\
\mathbf{F a}^{*} \\
\left(\mathbf{F r}^{* *} \%\right)\end{array}$ & $\begin{array}{c}\text { Náo } \\
\text { Fa* }^{*} \\
\left(\text { Fr }^{* * \%} \%\right)\end{array}$ & $\begin{array}{c}\operatorname{Sim}_{\mathbf{F a}^{*}} \\
\left(\mathbf{F r}^{* *} \%\right)\end{array}$ & $\begin{array}{c}\text { Não } \\
\text { Fa* }^{*} \\
\left(\mathrm{Fr}^{* *} \%\right)\end{array}$ & \\
\hline Nome completo do comprador & $473(96,9)$ & $15(3,1)$ & $251(99,2)$ & $2(0,8)$ & 0,067 \\
\hline Endereço completo do comprador & $456(93,4)$ & $32(6,6)$ & $243(96)$ & $10(4)$ & 0,180 \\
\hline Número do RG do comprador & $475(97,3)$ & $13(2,7)$ & $252(99,6)$ & $1(0,4)$ & 0,042 \\
\hline Carimbo e assinatura do farmacêutico & $59(12,1)$ & $429(87,9)$ & $4(1,6)$ & $249(98,4)$ & $<0,001$ \\
\hline Data da dispensaçáo & $475(97,3)$ & $13(2,7)$ & $252(99,6)$ & $1(0,4)$ & 0,076 \\
\hline Número do lote do medicamento & $485(99,4)$ & $5(0,6)$ & $252(99,6)$ & $1(0,4)$ & 0,670 \\
\hline
\end{tabular}

Fonte: Elaborado pelos autores a partir dos dados coletados.

Legenda: RG: Registro Geral; Fa*: frequência absoluta; $\mathrm{Fr}^{* *}$ : frequência relativa; ${ }^{* * *} \mathrm{p}$-valor $<0,05$.

\section{Informações obrigatórias na notificação de receita}

A notificação de receita por ser um documento padronizado deve obrigatoriamente conter algumas informaçóes essenciais, apresentadas na Tabela 3. Das 741 prescriçóes aviadas na farmácia em estudo, 677 foram dispensadas através da notificação de receita e 64 através de receituário de controle especial (branca). Das notificaçóes de receita, $51,1 \%$ apresentaram identificação da notificação B2, e 48,9\% não apresentaram.

A numeração da autorização da vigilância sanitária para confecção do talonário estava ausente em 29\% das notificaçóes do primeiro período e em 4,7\% no segundo período. A identificação numérica da notificação, a cor (azul) e a sigla da Unidade da Federação (BA) estavam adequadas em todas as notificaçóes do segundo período.

Tabela 3: Distribuição dos componentes obrigatórios da notificação de receita B2 de sibutramina, analisada em uma farmácia comunitária no município de Jequié/BA, entre janeiro de 2010 e junho de 2014.

\begin{tabular}{|c|c|c|c|c|c|}
\hline \multirow[b]{2}{*}{ Itens avaliados } & \multicolumn{2}{|c|}{ Jan/2010 a Dez/2011 } & \multicolumn{2}{|c|}{ Jan/2012 a Jun/2014 } & \multirow[b]{2}{*}{$\mathbf{p}^{* * *}$} \\
\hline & $\begin{array}{c}\text { Sim } \\
\mathrm{Fa}^{*} \\
\left(\mathrm{Fr}^{* *} \%\right)\end{array}$ & $\begin{array}{c}\text { Não } \\
\text { Fa* }^{*} \\
\left(\mathrm{Fr}^{* *} \%\right)\end{array}$ & $\begin{array}{c}\text { Sim } \\
\mathrm{Fa}^{*} \\
\left(\mathrm{Fr}^{* *} \%\right)\end{array}$ & $\begin{array}{c}\text { Náo } \\
\text { Fa* }^{*} \\
\left(\mathrm{Fr}^{* * \%)}\right.\end{array}$ & \\
\hline Presença da notificaçáo & $424(86,8)$ & $64(13,2)$ & $253(100)$ & $0(0)$ & $<0,001$ \\
\hline Identificaçáo da notificaçáo (B2) & $155(31,7)$ & $333(68,3)$ & $191(75,5)$ & $62(24,5)$ & $<0,001$ \\
\hline Identificação da gráfica & $423(86,6)$ & $65(13,4)$ & $252(99,6)$ & $1(0,4)$ & $<0,001$ \\
\hline Número da autorizaçáo da VISA & $346(70,9)$ & $142(29,1)$ & $241(95,2)$ & $12(4,8)$ & $<0,001$ \\
\hline Número da notificação & $421(86,3)$ & $67(13,7)$ & $253(100)$ & $0(0)$ & $<0,001$ \\
\hline Cor da notificaçáo (azul) & $424(86,8)$ & $64(13,2)$ & $253(100)$ & $0(0)$ & $<0,001$ \\
\hline Sigla da Unidade da Federaçáo (BA) & $424(86,8)$ & $64(13,2)$ & $253(100)$ & $0(0)$ & $<0,001$ \\
\hline
\end{tabular}

Fonte: Elaborado pelos autores a partir dos dados coletados.

Legenda: VISA: Vigilância Sanitária; Fa*: frequência absoluta; $\mathrm{Fr}^{* *}$ : frequência relativa; ${ }^{* * *}$ p-valor $<0,05$.

\section{Completude e legibilidade do termo de responsabilidade do prescritor}

A obrigatoriedade do termo de responsabilidade do prescritor teve início após a RDC 52/2011. Foram analisados 258 termos, seis foram de dezembro de 2011 quando a referida resolução entrou em vigor e
252 termos correspondentes ao período de janeiro de 2012 a junho de 2014. Apenas uma notificação não estava acompanhada do termo de responsabilidade do prescritor. A Tabela 4 apresenta a frequência das informaçôes que devem conter no termo de responsabilidade e que devem ser preenchidas pelo médico prescritor. 
Com relação ao nome do paciente, dez termos não apresentaram este item adequadamente preenchido. $\mathrm{O}$ item "idade" esteve ausente em 15\% dos termos, sendo que a idade dos pacientes esteve entre 19 e 65 anos, com média de 37,5 \pm 9,01 anos.

A identificaçáo do sexo do paciente não foi encontrada em 5,9\% dos termos. Dos pacientes, $89,3 \%$ eram mulheres e $10,7 \%$ homens. Também houve ausência ou ilegibilidade de informaçôes quanto ao endereço e telefone dos pacientes.

O diagnóstico apresentado pelo médico como indicação para a prescrição da sibutramina foi de sobrepeso $(4,2 \%)$, obesidade $(41,9 \%)$, obesidade com hipertensão arterial sistêmica $(3,7 \%)$, obesidade grau I ou leve (36,9\%), obesidade grau II $(7,5 \%)$ e obesidade grau III, severa ou mórbida $(5,8 \%)$.

Tabela 4: Distribuição dos componentes obrigatórios do termo de responsabilidade do prescritor para dispensação de sibutramina, analisada em uma farmácia comunitária no município de Jequié/BA, entre janeiro de 2010 e junho de 2014.

\begin{tabular}{|c|c|c|c|c|c|}
\hline \multirow[b]{2}{*}{ Itens avaliados } & \multicolumn{2}{|c|}{ Dez/2011 } & \multicolumn{2}{|c|}{ Jan/2012 a Jun/2014 } & \multirow[b]{2}{*}{$\mathbf{p}^{* * *}$} \\
\hline & $\begin{array}{c}\text { Sim } \\
\mathrm{Fa}^{*} \\
\left(\mathrm{Fr}^{* *} \%\right)\end{array}$ & $\begin{array}{c}\text { Náo } \\
\text { Fa* }^{*} \\
\left(\mathrm{Fr}^{* *} \%\right)\end{array}$ & $\begin{array}{c}\text { Sim } \\
\mathrm{Fa}^{*} \\
\left(\mathrm{Fr}^{* *} \%\right)\end{array}$ & $\begin{array}{c}\text { Náo } \\
\text { Fa* }^{*} \\
\left(\mathrm{Fr}^{* *} \%\right)\end{array}$ & \\
\hline Presença do termo de responsabilidade & $6(100)$ & $0(0)$ & $252(99,6)$ & $1(0,4)$ & $<0,001$ \\
\hline Nome completo do paciente & $6(100)$ & $0(0)$ & $242(95,6)$ & $10(4,4)$ & - \\
\hline Idade do paciente & $5(83,3)$ & $1(16,7)$ & $214(84,6)$ & $38(15,4)$ & - \\
\hline Sexo do paciente & $6(100)$ & $0(0)$ & $238(94,1)$ & $14(5,9)$ & - \\
\hline Número do RG do paciente & $5(83,3)$ & $1(16,7)$ & $226(89,3)$ & $26(10,7)$ & - \\
\hline Endereço do paciente & $5(83,3)$ & $1(16,7)$ & $193(76,3)$ & $59(23,7)$ & - \\
\hline Telefone do paciente & $5(83,3)$ & $1(16,7)$ & $194(76,6)$ & $58(23,4)$ & - \\
\hline Diagnóstico & $6(100)$ & $0(0)$ & $235(92,8)$ & $17(7,2)$ & - \\
\hline Assinatura do paciente & $6(100)$ & $0(0)$ & $217(85,7)$ & $35(14,3)$ & - \\
\hline Nome do prescritor & $6(100)$ & $0(0)$ & $241(95,2)$ & $11(4,8)$ & - \\
\hline Número do CRM & $6(100)$ & $0(0)$ & $241(95,2)$ & $11(4,8)$ & - \\
\hline Assinatura e carimbo do prescritor & $6(100)$ & $0(0)$ & $240(94,8)$ & $12(5,2)$ & - \\
\hline Data do termo & $6(100)$ & $0(0)$ & $229(90,5)$ & $23(9,5)$ & - \\
\hline
\end{tabular}

Fonte: Elaborado pelos autores a partir dos dados coletados.

Legenda: RG: Registro Geral; CRM: Conselho Regional de Medicina; Fa* frequência absoluta; Fr**: frequência relativa; ${ }^{* * *}$ p-valor $<0,05$.

\section{Discussão}

Os resultados obtidos apontam para uma redução do consumo de sibutramina e observa-se que o maior percentual de redução ocorreu em 2012 (46,7\%), período logo após a publicação da RDC 52/2011, que entrou em vigor em dezembro de 2011. Em estudo realizado em Videira, SC, também foi observado uma queda progressiva na venda de sibutramina após esta resolução que incluiu a sibutramina na lista de medicamentos B2 da Anvisa, com a exigência da notificação de receita azul, e continuou diminuindo depois da imposição do preenchimento do termo de responsabilidade do prescritor. Segundo os autores, essa queda que chegou a $61,11 \%$ em 2010, 24,7\% em 2011 e $20 \%$ em 2012 se deve ao controle mais rígido da venda desse medicamento imposto pelas novas resoluçóes ${ }^{11}$. Podemos perceber que essa maior rigorosidade para a venda da sibutramina também influenciou nas vendas da farmácia comunitária em estudo.

\section{Itens de preenchimento obrigatório pelo médico prescritor}

A Portaria 344/19985, do Ministério da Saúde, determina que as notificaçóes de receita só devam ser dispensadas se todos os dados obrigatórios estiverem preenchidos corretamente, por extenso, sem rasuras ou emendas. A notificação de receita é o documento que acompanhado de receita autoriza a dispensação de medicamentos à base de substâncias constantes nas listas A1 e A2 (entorpecentes), A3, B1 e B2 (psicotrópicas), C2 (retinoicas para uso sistêmico) e C3 
(imunossupressoras). A notificação de receita, de cor azul, terá validade de 30 (trinta) dias contados a partir de sua emissão e será válida apenas na Unidade Federativa que concedeu a numeração.

É de responsabilidade do prescritor o preenchimento dos seguintes itens: Identificação do paciente (nome e endereço completo); identificação de emitente (nome completo, número de inscrição do conselho profissional, nome e/ou endereço do consultório ou instituiçáo); nome do medicamento na denominação comum brasileira (DCB) ou comercial, dosagem ou concentração, forma farmacêutica, posologia e data de emissão; assinatura do profissional e carimbo 5 .

Os resultados obtidos nos dois períodos, no que se refere à identificação do paciente, foram melhores que os obtidos em Salto/SP onde se evidenciou falhas no preenchimento do endereço do paciente em $90 \%$ das notificaçóes e receitas ${ }^{12}$. O endereço do paciente foi também a falha mais encontrada, neste estudo $67,5 \%$ no primeiro período e $31,6 \%$ no segundo período, apresentando uma redução estatisticamente significativa no segundo período $(\mathrm{p}<0,001)$, o que aponta para um aumento da adesão à legislação, já que o preenchimento desse item e também do nome completo do paciente é essencial para qualquer contato que se faça necessário com o paciente.

O nome do prescritor, assinatura e número da inscrição no conselho profissional facilitam a identificação, localização e o contato com o prescritor em caso de dúvidas quanto ao tratamento. A ausência desses dados compromete a comunicação quando houver a necessidade por parte do dispensador ou do paciente de algum esclarecimento, o que pode contribuir para que ocorram erros ou abandono do tratamento. Em um estudo realizado no noroeste do estado do Rio Grande do Sul, a assinatura do médico foi verificada em pouco mais da metade de todas as prescriçóes avaliadas em um hospital de pequeno porte ${ }^{9}$. Neste estudo a ausência da assinatura e do nome do prescritor náo foi táo expressiva. Com a assinatura do prescritor ausente ou ilegível em 7,8\% das notificaçóes do primeiro período e em $4,4 \%$ no segundo ( $\mathrm{p}=0,086)$ e o nome do prescritor faltante em $6,6 \%$ no primeiro período e em $4,4 \%$ no segundo $(\mathrm{p}=0,250)$, a diferença entre os dois períodos não foi significativa provavelmente porque esses dados geralmente são impressos na própria notificação ou com o uso de carimbos.

Segundo Néri et al. ${ }^{13}$, essas informaçóes sobre a identificação do emitente, além de cumprirem aspectos técnicos e práticos no que se refere à comunicação com o prescritor, também garante validade legal à prescrição, portanto, quando estiverem omissas ou ilegíveis, as prescrições não devem ser dispensadas ou cumpridas.

Apesar de a legislação vigente no país estabelecer a adoção do nome genérico nas notificações de receitas de medicamentos e no caso dos serviços do SUS a obrigatoriedade da adoção da DCB ou denominação comum internacional (DCI), os resultados obtidos mostram uma preferência dos prescritores pelos medicamentos de marca que estiveram presentes em $62,3 \%$ das notificaçôes no primeiro período e em 49,4\% no segundo período ( $\mathrm{p}=0,001)$, valor próximo ao encontrado em estudo realizado com a prescrição de antimicrobianos em uma farmácia comunitária em Jequié, BA, mesma localidade deste estudo, onde a prescrição de medicamentos de marca foi de $72,5 \%{ }^{14}$, e em estudo realizado em Araraquara, SP, onde 43,3\% de todas as prescriçóes aviadas nas farmácias e drogarias eram medicamentos de marcas. Segundo o autor, essa não adesão à DCB pode comprometer o acesso aos medicamentos, pois o paciente fica sem a opção da escolha de um medicamento mais barato e de mesma segurança, qualidade e eficácia que o medicamento de marca ${ }^{8}$.

Houve também ilegibilidade ou ausência de informaçóes referentes à posologia e forma farmacêutica o que corrobora com resultados encontrados em outros estudos $^{12,13,14-17}$. A ausência de informaçôes sobre o medicamento e seu modo de uso pode gerar erros na dispensação e o abandono do tratamento pelo paciente. A falta da forma farmacêutica é imprescindível quando os medicamentos são comercializados em diferentes formas farmacêuticas e apresentações, o que não se aplica à sibutramina que é comercializada apenas em cápsulas, apesar de $32 \%$ das notificaçóes registrarem a forma comprimido neste estudo. A posologia é outro item indispensável para a correta administração do medicamento, pois intervalos maiores entre as doses podem provocar redução do resultado esperado, e intervalos menores podem aumentar os riscos de reaçóes adversas. Nas informaçôes sobre o medicamento (concentraçáo, forma farmacêutica, posologia), também verificou-se diferença estatisticamente significante entre os dois períodos $(\mathrm{p}<0,001)$ para todas as variáveis, pois o preenchimento desses dados ficou mais completo e legível no segundo período em funçáo do maior rigor na dispensação imposta pela RDC 52/2011.

Além dos quesitos mencionados anteriormente, a ausência da data da notificação impede que o profissional dispensador conheça a validade da prescrição, podendo trazer prejuízos à boa orientação farmacêutica. Além disso, a falta do preenchimento desse campo pode levar a fraudes e ao uso irracional do medicamento, pois o paciente decidirá a data da compra e do uso do medicamento ${ }^{8,18}$. Arruda et at. ${ }^{16}$ encontraram ausência da data em $74 \%$ das prescriçóes avaliadas, número superior ao encontrado neste estudo que foi de $28,5 \%$ no primeiro período e $7,5 \%$ no segundo período $(\mathrm{p}<0,001)$, já que houve aumento da fiscalização sanitária a partir de uma operação de fiscalização da Anvisa com a Polícia 
Federal, exigindo mais atenção no cumprimento dos requisitos obrigatórios para prescrição e dispensação de medicamentos ${ }^{19}$.

Apesar da variedade de especialidades médicas apresentada neste estudo, os clínicos gerais foram os que mais prescreveram. $\mathrm{O}$ que também se observou em estudos sobre a prescrição de medicamento para o tratamento da obesidade em Videira ${ }^{11}$, SC, onde $43,03 \%$ das receitas prescritas eram de clínicos gerais, $13,68 \%$ de cirurgióes gerais, $10,95 \%$ de ginecologistas e $9,45 \%$ de endocrinologistas. Já em Ijuí ${ }^{20}$, RS, os endocrinologistas foram $41,25 \%$, os clínicos gerais $26,25 \%$ e os ginecologistas $10 \%$ das prescriçóes para tratamento da obesidade.

A Associação Brasileira para o Estudo da Obesidade e da Síndrome Metabólica (Abeso) ${ }^{21}$ orienta que os medicamentos para casos específicos do tratamento da obesidade devem ser prescritos por médicos com experiência no manejo da doença e com conhecimentos específicos dos medicamentos. Neste estudo observou-se que grande parte das prescriçóes foi emitida por clínicos gerais nos dois períodos. Segundo Borges et al. ${ }^{22}$, prescriçóes emitidas por outros especialistas não deveriam ser comuns, pois os endocrinologistas são os profissionais habilitados para o tratamento da obesidade, no entanto, náo há obrigatoriedade, apenas uma orientaçáo.

\section{Itens de preenchimento obrigatório pelo profissional dispensador}

Com relação aos itens que são de responsabilidade do farmacêutico preencher no momento da dispensação, a Portaria 344/19985 informa que deve constar na notificação de receita nome completo, número do documento de identificação (RG) e endereço completo do comprador; carimbo e assinatura do farmacêutico, data da dispensação, número do lote do medicamento dispensado e a quantidade dispensada.

Observou-se neste estudo que a prevalência de ausência e ilegibilidade dos dados do comprador foram baixas, o que difere de outros estudos ${ }^{16,23}$. Em geral, são os próprios compradores que preenchem esses campos, o que justifica sua completude e legibilidade na maioria das notificaçóes dos dois períodos analisados. A identificação do comprador é importante, pois nem sempre é o paciente quem compra o medicamento e, dessa forma, o destino final do medicamento pode náo ser o endereço do paciente. Segundo Ferrari et al..$^{23}$, também é importante como mecanismo de controle para se evitar erros e fraudes.

A data da dispensação garante que a notificação foi aviada dentro do seu prazo de validade legal, que no caso da sibutramina é de 30 dias. Todas as notificaçóes aviadas no período deste estudo foram dispensadas dentro do prazo de validade legal. $\mathrm{E}$ o registro do lote do medicamento vendido é necessário para que o farmacêutico realize o registro do medicamento e controle do estoque no sistema nacional de gerenciamento de produtos controlados (SNGPC). Esses itens não apresentaram diferença estatística entre os dois períodos, pois essas exigências veem com a implantação do SNGPC em 2007, data anterior ao estudo. Já o item carimbo e assinatura do farmacêutico estiveram ausentes em $87,9 \%$ no primeiro período e em $98,4 \%$ no segundo período, em Pontal do Araguaia ${ }^{23}$, MT, não esteve presente em nenhuma das prescrições avaliadas. Percebe-se que essa informação é negligenciada pelos farmacêuticos, pois entendem como desnecessário já que as notificaçôes ficam retidas na farmácia, o que é um equívoco visto que as notificações ficam retidas para verificação da vigilância sanitária.

Também é de responsabilidade do farmacêutico o registro da quantidade dispensada, assim como é de responsabilidade do prescritor registrar a quantidade prescrita. Esses itens estavam presentes e legíveis em todas as notificaçóes avaliadas neste estudo. Porém observou-se divergência entre essas quantidades, porque nem sempre o paciente compra a quantidade prescrita, ou porque houve discordância entre a posologia e o número de unidades prescritas. Segundo a RDC $58 / 2007^{6}$, as notificaçóes de receita B2 devem ter a quantidade para o tratamento de no máximo 30 dias, e a RDC 52/2011 determina a dose máxima diária para a sibutramina de $15 \mathrm{mg}$.

\section{Informações obrigatórias na notificação de receita}

Com relação aos dados da notificação de receita, devem constar impressos no rodapé a identificação da gráfica (nome, endereço, CNPJ/CGC, numeração inicial e final do talonário, número da autorização para confecção do talonário emitido pela Vigilância Sanitária), a sigla da Unidade Federativa e a identificação da notificação (B2), cor e número da notificação.

No primeiro período considerado no estudo, foram analisadas 424 notificaçóes de receita e 64 receitas de controle especial (branca) contendo a prescrição do medicamento sibutramina, porque ainda fazia parte da lista C1. A partir de 2010, passou a vigorar a RDC 25, de 30 de junho de 2010, que determinou que essa substância fosse prescrita em notificação de receita B2. No segundo período, todas as prescrições analisadas foram em notificaçóes de receita. Comparando os dois períodos, temos uma diferença estatística $(\mathrm{p}<0,001)$ que indica o cumprimento da legislação. 
Também foram avaliadas as notificaçóes quanto à identificação e a cor que, no caso da sibutramina seguindo a Portaria 25/2010, deve ser B2 e de cor azul. No primeiro período $31,7 \%$ das notificaçóes eram B2 e no segundo período 75,5\% ( $\mathrm{p}<0,001)$. Quanto à cor, no primeiro período $86,8 \%$ apresentavam cor azul, e no segundo período $100 \%(\mathrm{p}<0,001)$. Portanto, observa-se maior concordância com a legislação no segundo período, por reflexo da intensificação da fiscalização ou por maior divulgaçáo e conhecimento da legislação por parte dos profissionais envolvidos na prescrição e dispensaçáo de medicamentos.

A numeração de autorização da VISA (Vigilância Sanitária) para confecção do talonário de notificação e a identificação da gráfica que confeccionou as notificações são informaçóes que garantem legitimidade e legalidade às notificaçōes. Sua presença é fundamental para que o paciente e o farmacêutico tenham como verificar com as autoridades fiscalizadoras a veracidade do documento.

$\mathrm{O}$ número de autorização da VISA esteve presente em 70,9\% das notificaçóes do primeiro período e em $95,2 \%$ no segundo período $(\mathrm{p}<0,001)$, percentual maior que o encontrado no estudo em Pontal do Araguaia ${ }^{23}$, onde $58 \%$ das notificaçóes de psicotrópicos em uma farmácia básica não apresentavam esse dado, quando comparado com o encontrado em Ribeiráo Preto ${ }^{24}$, SP, onde $85,2 \%$ das notificaçóes e receitas retidas em farmácias de manipulação não tinham esse dado. A identificação completa da gráfica contendo nome, endereço e CNPJ/CGC também foi mais presente $99,6 \%$ no segundo período do que no primeiro $86,6 \%(\mathrm{p}<0,001)$. Em Pontal do Araguaia, esse valor foi de 99,2\%, e em Ribeirão Preto $100 \%$.

Todas as notificações analisadas continham a Unidade da Federação correspondente a Bahia (BA), e a identificação numérica da notificação faltou em 13,4\% no primeiro período e em apenas uma $(0,4 \%)$ no segundo $(\mathrm{p}<0,001)$.

Comparando-se os dois períodos, antes e após a RDC 52/2011, percebe-se, que de uma forma geral, com o aumento da fiscalização sanitária e conscientização dos profissionais envolvidos na prescrição e dispensação da sibutramina, as falhas e incompletudes ficaram menos presentes no segundo período pelas diferenças estatisticamente significativas.

\section{Completude e legibilidade do termo de responsabilidade do prescritor}

O termo de responsabilidade do prescritor é o documento que assinado pelo paciente garante que este recebeu do médico todas as informaçóes necessárias sobre os cuidados e possíveis riscos quanto ao uso do medicamento. Deve acompanhar a prescrição e ser preenchido em três vias: uma via deve ser arquivada no prontuário do paciente; a outra na farmácia ou drogaria dispensadora e uma via mantida com o paciente. Também obriga o médico e o farmacêutico a notificarem no Sistema Nacional de Notificaçôes para a Vigilância Sanitária (Notivisa) qualquer evento adverso relacionado ao uso de medicamento que contenha a substância sibutramina, seus sais e isômeros, bem como intermediários, sendo de notificação compulsória ao Sistema Nacional de Vigilância Sanitária .

A exigência desse documento para a dispensação da sibutramina iniciou depois que a RDC 52 entrou em vigor em dezembro de 2011. Dos 258 termos analisados, seis foram de dezembro de 2011 e 252 termos correspondentes ao período de janeiro de 2012 a junho de 2014. Apenas uma notificação não estava acompanhada do termo de responsabilidade do prescritor nesse período. Quando comparamos os dois períodos, percebemos uma diferença estatisticamente significativa para a presença ou não do termo entre os dois períodos, isso já era esperado, pois antes da RDC 52/2011 (primeiro período), o termo náo era obrigatório $(\mathrm{p}<0,001)$.

Não foram encontrados na literatura trabalhos relacionados ao termo de responsabilidade do prescritor para o uso de sibutramina. Para alguns autores ${ }^{25}$, a exigência de termos como o exemplo do termo de consentimento para o uso da talidomida, quando aplicado por profissionais mal habilitados ou não comprometidos, transfere a responsabilidade do tratamento e do uso do medicamento para o paciente, pois mesmo com a rigorosidade da legislação vigente, nos últimos anos ocorreram casos de focomelia registrados no país relacionado ao uso da talidomida, demonstrando não efetividade da legislação vigente.

A identificação do paciente (nome, número do documento de identificação, endereço e telefone) também é importante e precisa estar adequadamente preenchida, pois além de identificar o paciente, possibilita o contato com ele caso necessário. A assinatura do paciente é a garantia do prescritor de que ele forneceu todas as informaçôes referentes ao uso do medicamento, suas restriçóes e está ciente dos riscos do tratamento.

A média de idade dos pacientes foi de 37,5 $\pm 9,01$ anos. De acordo com o termo de responsabilidade, o uso da sibutramina está contraindicado para pacientes com idade acima de 65 (sessenta e cinco) anos, crianças e adolescentes.

As mulheres foram maioria $(89,3 \%)$ dos pacientes, assim como em outros estudos sobre a prescrição de medicamentos para tratamento da obesidade ${ }^{26}$, no qual as mulheres representaram $68 \%$, e sobre a prescrição de psicotrópicos ${ }^{23}$, em que verificou-se que as mulheres eram $72,8 \%$ dos pacientes. Segundo Oliveira e 
Buzanelo $^{20}$, as mulheres são mais influenciadas pelo culto à beleza e aos corpos magros, portanto, faz-se necessário a implementação de parâmetros técnicos e fiscalização que favoreçam o uso racional de medicamentos.

$\mathrm{O}$ diagnóstico indicado pelo CID (Código Internacional de Doenças) ou por extenso é um dos itens do termo que deve ser preenchido pelo médico como indicação para a prescriçáo da sibutramina, neste estudo este dado esteve ausente em 7,2\% dos termos.

A diretriz para o tratamento da obesidade da Abeso/SBEM-2010 $0^{21}$ recomenda o uso de medicamentos no tratamento da obesidade e sobrepeso para os pacientes: com IMC (índice de massa corporal) igual ou superior a $30 \mathrm{~kg} / \mathrm{m}^{2}$; com IMC igual ou superior a $25 \mathrm{~kg} / \mathrm{m}^{2}$ associado a outros fatores de risco, como a hipertensão arterial, Diabetes Mellitus tipo 2, hiperlipidemia, apneia do sono, osteoartrose, gota, entre outras; ou com circunferência abdominal maior ou igual a $102 \mathrm{~cm}$ (homens) e $88 \mathrm{~cm}$ (mulheres). E classifica como sobrepeso - pacientes com IMC $\geq 25$; pré-obeso - IMC entre 25-29,9; obeso I - IMC entre 30,0-34,9; obeso II - IMC entre 35,0-39,9; obeso III - IMC $\geq 40$. Dessa forma, pode-se perceber a inadequação da prescrição para os pacientes com sobrepeso que foram $4,1 \%$ dos termos analisados, já que náo foram relatados fatores de risco associados. Em estudo realizado em Maringá ${ }^{26}$, PR, sobre o uso de anorexígenos por acadêmicas de instituição de ensino superior, 55,84\% das usuárias de anorexígenos possuíam o peso normal e dentre as que apresentavam sobrepeso apenas 1,3\% havia indicação do uso do medicamento por ter patologia associada.

Neste trabalho foi testada a associação entre as variáveis estudadas. A análise estatística mostrou que houve aumento na completude e legibilidade dos documentos legais para a venda da sibutramina, a notificação de receita B2 e o termo de responsabilidade do prescritor no segundo período, após a RDC 52/2011, período em que também houve aumento da fiscalização sanitária. Porém ressalta que ainda é necessária a implantação de estratégias educativas que reforcem a prescrição e dispensação adequadas para a promoçáo do uso racional de medicamentos.

\section{Conclusões}

Os resultados obtidos neste estudo demonstram falhas no preenchimento legal dos documentos obrigatórios para a dispensação de sibutramina: a notificação de receita tipo $\mathrm{B} 2$ e o termo de responsabilidade do prescritor, visto que náo foi encontrada na amostra uma notificação de receita que atendesse a todos os requisitos exigidos. Porém foi observado aumento estatístico da completude e legibilidade desses documentos, do primeiro para o segundo período, evidenciando o impacto positivo das novas legislaçóes na comercialização de sibutramina. Também foi possível traçar o perfil de consumo de sibutramina no município de Jequié-Bahia, com diminuiçáo das vendas no segundo período e predominância de prescrição com nome de marca em detrimento do genérico.

\section{Referências}

1. World Health Organization. Obesity: preventing and managing the global epidemic. Report of a WHO consultation. World Health Organ Tech Rep Ser. 2000;894:1-253.

2. Coutinho W. The first decade of sibutramine and orlistat: a reappraisal of their expanding roles in the treatment of obesity and associated conditions. Arq Bras Endocrinol Metab. 2009;53(2):262-70.

3. Zanella MT, Ribeiro Filho FF. Emerging drugs for obesity therapy. Arq Bras Endocrinol Metab. 2009;53(2):271-80.

4. Agência Nacional de Vigilância Sanitária (Brasil). Resolução da Diretoria Colegiada no 52, de 6 de outubro de 2011. Dispóe sobre a proibição do uso das substâncias anfepramona, femproporex e mazindol, seus sais e isômeros, bem como intermediários e medidas de controle da prescrição e dispensação de medicamentos que contenham a substância sibutramina, seus sais e isômeros, bem como intermediários e dá outras providências. Brasília, DF; 2011.

5. Agência Nacional de Vigilância Sanitária (Brasil). Portaria $\mathrm{n}^{\circ}$ 344, de 12 de maio de 1998. Aprova o Regulamento Técnico sobre substâncias e medicamentos sujeitos a controle especial. Brasília, DF; 1998.

6. Agência Nacional de Vigilância Sanitária (Brasil). Resolução da Diretoria Colegiada no 58, de 5 de setembro de 2007. Dispõe sobre o aperfeiçoamento do controle e fiscalização de substâncias psicotrópicas anorexígenas e dá outras providências. Brasília, DF; 2007.

7. Agência Nacional de Vigilância Sanitária (Brasil). Resolução da Diretoria Colegiada no 50, de 25 de setembro de 2014. Dispóe sobre as medidas de controle de comercialização, prescrição e dispensação de medicamentos que contenham as substâncias anfepramona, femproporex, mazindol e sibutramina, seus sais e isômeros, bem como intermediários e dá outras providências. Brasília, DF; 2014.

8. Mastroianni PC. Análise dos aspectos legais das prescriçóes de medicamentos. Rev Ciênc Farm Básica Apl. 2009;30(2):45-8.

9. Weber D, Bueno CS, Oliveira KR. Análise das prescrições medicamentosas de um hospital de pequeno porte do noroeste do Estado do Rio Grande do Sul. Rev Ciênc Farm Básica Apl. 2012;33(1):139-45.

10. Instituto Brasileiro de Geografia e Estatística. IBGE Cidades: Jequié. 2014. 
11. Viero TR, Locateli C. Perfil de prescrição e comparativo de vendas de sibutramina antes e após RDC no 25 de 30 de junho de 2010 e RDC no 52 de 06 de outubro de 2011 em uma farmácia da cidade de Videira-SC. RIES. 2013;2(1):8-17.

12. Camargo MDF, Lopes AM, Montebelo MI, Lopes LC. Avaliação da adesão às normas da portaria 344/98 SVS/ MS utilizando notificações e receitas oriundas da cidade de Salto/SP. Rev Ciênc Farm Básica Apli. 2005;26(2):131-37.

13. Néri EDR, Gadêlha PGC, Maia SG, Pereira AGS, Almeida PC, Rodrigues CRM, et al. Erros de prescrição de medicamentos em um hospital brasileiro. Rev Assoc Med Bras. 2011;57(3):306-14.

14. Alves CDS, Lemos GS. Análise da completude das prescriçóes médicas de antimicrobianos dispensadas em uma farmácia comunitária no município de Jequié-BA. [Trabalho de conclusão de curso]. Jequié: Universidade Estadual do Sudoeste da Bahia; 2013.

15. Conselho Federal de Medicina (Brasil). Manual de orientaçôes básicas para prescrição médica. 2a ed. Brasília, DF: Conselho Regional de Medicina da Paraíba; 2011. 62p.

16. Arruda EL, Morais HLMN, Partata A. Avaliação das informaçóes contidas em receitas e Notificaçóes de receitas atendidas na farmácia do CAPS II Araguaína-TO. Rev Científica do ITPAC. 2012;5(2):1-14.

17. Ev LS, Guimarães AG, Castro VS. Avaliação das prescriçóes dispensadas em uma Unidade Básica de Saúde do Município de Ouro Preto, Minas Gerais, Brasil. Lat Am J Pharm. 2008;27(4):543-47.

18. Lins BG, Cazzamalli F, Zancanaro V. Análises de erros nas prescrições médicas de uma unidade básica de saúde de um município do Meio Oeste Catarinense. RIES. 2012;1(2):62-77.
19. Costa S. PRF e Anvisa fecham farmácias durante operação no interior do estado. Correio-Rede Bahia. [acesso em 2011 jan. 26]. Disponível em: http://www.correio24horas.com. $\mathrm{br} /$ detalhe/noticia/prf-e-anvisa-fecham-farmacias-durante-operacao-no-interior-do-estado/

20. Oliveira KR, Buzanelo VV. Análise das prescriçóes de medicamentos usados no tratamento da obesidade dispensadas em drogaria no município de Ijuí-RS. Rev Ciên Farm Básica Apl. 2011;32(3):381-7.

21. Associação Brasileira para o estudo da obesidade e síndrome metabólica. Atualização das Diretrizes para o Tratamento Farmacológico da Obesidade e do Sobrepeso. Posicionamento Oficial da ABESO/SBEM-2010. ABESO 76. São Paulo; 2010. 21.

22. Borges GPM, Belo T, Vieira GMM, Vieira JRS. Análise dos receituários de medicamentos psicotrópicos anorexígenos em uma rede privada de farmácia de Belém-Pará. Infarma. 2008;20(9-10):26-31.

23. Ferrari CKB, Brito LF, Oliveira CC, Moraes EV, Toledo OR, David FL. Falhas na prescrição e dispensação de medicamentos psicotrópicos: um problema de saúde pública. Rev Ciênc Farm Básica Apl. 2013;34(1):109-16.

24. Andrade MF, Andrade RCG, Santos V. Prescrição de psicotrópicos: avaliação das informaçôes contidas em receitas e notificações. Rev Bras Ciên Farm. 2004;40(4):471-79.

25. Matta SR, Miranda ES, Osorio-de-Castro CGS. Prescrição e dispensação de medicamentos psicoativos nos instrumentos normativos da regulaçáo sanitária brasileira: implicaçóes para o uso racional de medicamentos. Rev Bras Farm. 2011;92(1):33-41.

26. Silva MC, Campesatto-Mella EA. Avaliação do uso de anorexígenos por acadêmicas de uma instituição de ensino superior em Maringá, PR. Arq Ciênc Saúde Unipar. 2008;12(1):43-50.

\section{Como citar este artigo:}

Souza SSS, Pinheiro MTRS, Almeida PHRF, Lemos LB, Lemos GS. Sibutramina: falhas e incompletude de documentos na prescrição e dispensação. Rev. Aten. Saúde. 2017;15(51):23-33. 